UDC 579.25

\title{
GENETIC HISTORY OF SHEEP DOMESTICATION
}

\author{
Atavliyeva S., Tarlykov P. \\ National Center for Biotechnology \\ 13/5, Korgalzhyn road, Astana, 010000, Kazakhstan \\ atavlievas@gmail.com
}

\begin{abstract}
Domestication of sheep in the Fertile Crescent region of the Near East is an important evolutionary and historical event. Modern DNA analysis of sheep remains can complement knowledge obtained through morphological analysis at archaeological sites. In particular, investigation of mitochondrial DNA and endogenous retroviral sequences are widely used for studying the domestication, migration, and origin of domestic sheep. Comparison of the mitochondrial genomes of wild and modern sheep has further facilitated investigations on the origin of domestic sheep, indicating that the mouflon (Ovis orientalis) is the ancestor of domesticated sheep. To date, five phylogenetically divergent lineages of mitochondrial DNA have been identified in domestic sheep. Migration events from the center of domestication were studied in detail using retroviral integration. This progress highlights the need to conduct further genetic studies of modern and ancient samples of sheep so as to gain a more in-depth understanding of domestication events, migration processes, and the formation of basic breeds of domestic sheep.
\end{abstract}

Key words: domestication, Ovis aries, mitochondrial DNA, retroviruses.

\section{INTRODUCTION}

About 11,000 years before the present (BP) in the countries of the Near East new approaches were applied in agriculture, which enabled humans to cultivate legumes and cereals, and domesticate certain species of animals. Domestication had redirected human communities from hunters and gatherers to agriculture, which gradually led to the Neolithic revolution. The spread of the Neolithic culture began from the countries of the Fertile Crescent to the territory of Europe, to the south to North Africa, and to the east to Western and Central Asia [1].Due to their rapid adaptation, sheep and goats were the first animals to go through the process of domestication, which made them the most important resource in human society. Domestication influenced the behavior, phenotype and genotype of these animals, which were selected for such features as the color and quality of wool, the production of meat and milk. Thousands of years of breeding have led to the spectrum of phenotypic differences among breeds [2, 3, 4].

It is known that sheep were domesticated in the countries of the Fertile Crescent about 11000 years ago. Hunting for wild sheep led to a decrease in their livestock in human habitats, prompting people to move to controlled hunting in order to avoid the threat of complete extinction of populations of wild sheep. Over time, controlled hunting switched to breeding and management of the herd, and subsequently it contributed to domestication [5].Study of archaeological evidences of domestication prior to the 1990s was mainly focused on morphological changes in bones. It was found that the first obvious signs of domestication in sheep appeared 9500$9000 \mathrm{BP}$, which was accompanied by a change in the shape of the horns [1].

It should be noted that with the development of sequencing in the 2000s, researchers have acquired new methods to study and understand the dynamics of domestication and domestication of animals. This paper provides an overview of published works in the field of domestication of small cattle, including with the study of phylogeny of sheep, the origin of domestic sheep, and ending with the discussion of migration routes for the genus Ovis.

\section{APPROACHES TO STUDY GENETIC DIVERSITY IN DOMESTIC SHEEP}

With the development of modern genetic techniques, it became possible to compare the genomes of modern breeds of domestic animals with wild sheep, as well as the study of ancient DNA (aDNA) of sheep remains. Use of mitochondrial DNA (mtDNA) and retroviral integration markers are widespread for tracing domestication, migration of sheep and for the ancestor of the domestic sheep.

\section{mtDNA}

Mitochondrial DNA is one of the most common objects for studying the phylogeny of the genus Ovis. Mitochondrial DNA is inherited through oocytes, which allows one to track the genetic lineage of ancestors without recombination events. An additional advantage of mtDNA in the study of archaeological samples is that 
mitochondrial DNA is present in multiple copies per cell. Thus, the probability of degradation of multiple copies of mtDNA is much lower than that of nuclear DNA [6].

The mitogenome from domestic sheep ranges in size from 16616 to $16620 \mathrm{bp}$ [7]. The sequence analysis of control region (1180 bp) and $c y t B$ gene $(1140 \mathrm{bp})$ is used in genetic diversity studies. The control region contains tandem repeats, each repeat consisting of two octameric sequences (TTAATGTA, TACATTAA), which form the conserved D-loop. For the first time the divergence of the sheep, based on the variability of mtDNA control region was revealed by Wood and Phua, dividing the New Zealand sheep on two main haplogroup [7, 8].

In 1998, Hiendlederde scribed the origin of mtDNA haplogroups, examining the modern breeds of Eurasia, came to the conclusion that the frequency of occurrence of haplogroups is different. For example, haplogroup A occurs more often in Asia, while haplogroup B is more common among European breeds of sheep. Haplogroup C was simultaneously detected by two groups of scientists Guo and Pedrosa, among a sample of domestic breeds of sheep in China and Turkey, respectively [9, 10]. Haplogroup $\mathrm{C}$ was also recorded at a low frequency in sheep breeds, common both in Portugal and the Middle East, leading to the hypothesis of the migration of sheep from the Fertile Crescent to the Iberian Peninsula in the past $[11,12]$.

Nowadays, there are five phylogenetically divergent haplogroups of sheep based on mtDNA. The most recent were the haplogroups D and E, which were discovered during the study of the sheep of the North Caucasus and Turkey (fig. 1) [13]. The nucleotide sequences of these groups formed separate clusters on a phylogenetic tree, including the haplogroups A, B and C $[14,15]$.

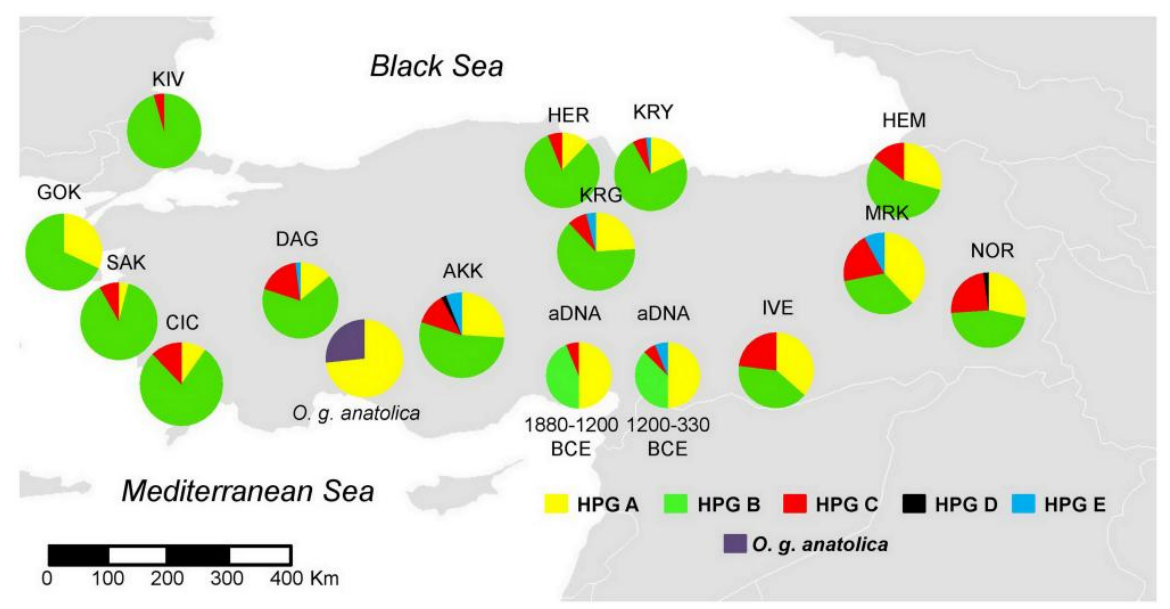

Circular diagrams are located according to the geographic distribution modern species, habitat Ovis gmelinii anatolica and the region of archeological excavations aDNA

Fig. 1. Distribution haplogroups of modern species of sheep, aDNA and Ovis gmelinii anatolica on the map of Turkey

The genetic relationship of the five haplogroups to mitochondrial sequences of the $c y t-B$ gene showed that the haplotypes are divided into two clusters, the haplogroups A, B, and D have merged into the first cluster; and haplogroups C, E has merged into the second [13]. Previously, Meadows indicated different lengths of the control region in repetitive sequences of $75 \mathrm{bp}$ or $76 \mathrm{bp}$ [12]. Interestingly, this difference is a marker for dividing into two clusters of haplogroups: A, B, D (75 bp) and C, E (76 bp) [13].

At present, it is assumed that only one or two haplogroups are associated with domestication processes, while the others are formed as a result of introgression with wild species. Initially, it was revealed that haplogroups A and $\mathrm{B}$ were the main ones, and their division occurred sequentially, group A appeared first, and later it divided into group B. In addition, a greater genetic diversity was found for haplogroup C than A or B [16].

Later studies of modern breeds of sheep confirmed the finding of Hiendleder, that in Asia (India, Indonesia, Mongolia, Tibet) the occurrence of haplogroup A is higher, and in Europe (Austria, Finland, Spain and northwestern Russia) the occurrence of haplogroup B is higher than A. This distribution has revealed that sheep have the highest level of diversity among domestic animals at the continental level. Only $2.7 \%$ of the observed variations in the mtDNA nucleotide sequence were unique within the continent, which is less than in goats (10\%) and in cattle $(50 \%)$. At the same time about $75 \%$ of modern breeds of sheep retained impressive sizes of subpopulations, which is higher than in cattle or dogs [17].

Domestication and selection of sheep led to the formation of a whole set of breeds selected for the production of wool, milk and meat. A wide variety of species indicates a highly heterogeneous population of wild Ovis species from which Ovis aries were domesticated, and the "bottleneck effect" did not seriously affect the sheep population as in some other domestic animals. The study of modern breeds of sheep has revealed the spread of haplotypes having a short time of divergence, which indicates a frequent genetic exchange that occurred during the formation of modern breeds of sheep. Studies confirm that individual regions of the genome have accelerated evolutionary 
development in response to artificial selection. In addition, backcrossing with wild sheep populations, which takes place after the initial domestication events, is highly possible [3].

Thus, to date, five phylogenetically divergent mtDNA groups have been found in domestic sheep, with haplogroups A and B occurring in most modern breeds of sheep, while haplogroups C, D, E have limited geographical distribution $[12,14]$. The study of mtDNA is focused on the maternal origin of domestic sheep and their potential predecessors. This genetic marker has a number of disadvantages. Non-coding mtDNA cannot provide comprehensive information about the phenotype, loci of selection, and the flow of genes between populations. Therefore, many questions concerning the domestication process cannot be solved only by the study of mtDNA [6].

\section{Retroviruses}

Retroviruses have a unique replication cycle that facilitates the integration of viral DNA into the host genome, resulting in provirus formation. According to the type of transfer of genetic material, there are two types of retroviruses: 1) exogenous that affect somatic cells and are transmitted horizontally from the infected organism to the uninfected; 2) endogenous that affect the cells of the germ line and become permanent elements of the genome, transferred vertically to the offspring according to Mendel's law [18].

Retroviruses can be used as genetic markers, since the presence of each endogenous retrovirus in the genome is the result of integration into the body and is irreversible. Populations of animals that share the same provirus in the same genomic site are phylogenetically related. Endogenous retroviral marker in sheep is Jaagesiekte sheep retrovirus (enJSRV), is the causative agent of sheep pulmonary adenocarcinoma. This disease of sheep is common all over the world [19].

The enJSRV genome length is about $7500 \mathrm{bp}$. Similar to many other retroviruses, it encodes the genes gag, pro, pol and env, and also contains an open reading frame in the form of mRNAs (3.2 kb)coding a protein 179 amino acids in length with unknown function. In the sheep genome, approximately 27 species of endogenous retrovirus loci are found, some of them are differentially distributed between the breeds, forming polymorphic forms.

Most enJSRV loci are present in the genome as defective genes of the virus with premature terminal codons, multiple deletion sites and/or recombinations. Entire genomic organizations and continuous reading frames have five loci enJSRV (enJSRV-7, enJSRV-15, enJSRV-16, enJSRV-18 and enJSRV-26). The intact open reading frames have sixteen loci, except enJSRV-4 and enJSRV-24, with some genes missing. Interestingly, the 5'and 3' LTR regions are the same in the enJSRV-15, enJSRV-16, enJSRV-18 and enJSRV-26 loci, which may be the cause of recent integration into the host germline. This hypothesis is supported by the fact that two loci, enJSRV-16 and enJSRV-18, are completely identical to each other in all genes [18, 19].

Studies of the sheep genome on retroviral integration among 133 breeds of domestic sheep and 3 species of wild sheep have revealed that the highest incidence rate is observed at the enJSRV-18 locus (85\%). The enJSRV-7 and enJS5F16 loci are found among $27 \%$ and $30 \%$ of the samples respectively, the rarest enJSR V-15, enJSRV-16 and enJSRV-8 loci are present in only 3-5\% of the samples [19].

By the distance between the 5' and 3'LTR regions of the erv locus, it is possible to calculate the "age" of the provirus, on the assumption that when infected, retroviruses transcribe their genome from RNA to DNA, which leads to a doubling of the genomic ends and the occurrence of two identical LTRs. When integrating the LTR, the areas of the endogenous virus are identical, but according to the principle of non-coding sequences and with the same speed they may diverge with time $\left(\sim 2.3 \times 10^{-9}\right.$ to $5 \times 10^{-9}$ replacements of each site per year). Based on this rule, enJSRV-7 is one of the oldest proviruses in the sheep genome, since it contains five nucleotide substitutions between 5' and 3' LTR (445 bp), the remaining proviruses have the same LTR regions. These data indicate that enJSRV-7 is possibly associated with the domestication process, and the remaining enJSRVs were introduced into the sheep genome later [19].

Thus, retroviral inserts can serve as an additional marker in the study of migration processes and the formation of the basic breeds of domestic sheep, as well as the search for their common ancestor.

\section{Y-chromosome}

There are fewer studies conducted on Ovis aries Y-chromosome than other genetic markers in spite of the fact that $\mathrm{Y}$ chromosome represents "paternal line" and supplements the phylogenetic data obtained by mtDNA and retroviral insertions analysis.

The currently studied Y-chromosomal markers can be divided into two types: fragment of the sex-determining region Y gene (SRY) and microsatellite SRYM18. The Y-chromosomal SRY gene has two alleles (A-oY1 and GoY1), identified by one SNP (A/G). SNP analysis revealed that the A-oY1 allele is present in the genome of wild species: Ovis canadensis, Ovis dalli, Ovis musimon. In addition, the high incidence of A-oY1 (71.4\%) has been found in a sample of domestic sheep, consisting of 65 breeds collected from around the world. The results show that A-oY1 is a wild-type allele, and G-oY1 allele may have appeared after the domestication of Ovis aries [20]. Interestingly, the aDNA of the sheep from Finland contains exclusively the G-oY1 allele, while the incidence of this allele in modern Finnish breeds is about 65\%. According to Meadows, the frequency of occurrence of G-oY1 is high 
in Northern Europe, the British Isles, and Central Russia. The authors suggest that the sheep migrated to Finland through Russia and afterward to Northern Europe [21].

The study of the microsatellite SRYM18 identified 11 haplotypes on the "paternal line". The frequency of haplotypes does not depend on the geographic region of the sheep population. For example, the most frequent H6 haplotype was common in all modern domestic breeds, while the remaining haplotypes were not informative. As suggested by the authors, "A high rate of Y chromosomal dispersal appears to have taken place during the development of domestic sheep as only $12.9 \%$ of the total observed variation was partitioned between major geographical regions" [20].

Although the analysis of Y chromosome has shown to be less informative than other DNA markers it made possible to evaluate the genetic relationship of sheep to its wild relatives and to supplement the history of migration of sheep to Europe.

\section{SEARCH FOR THE OVIES AIES ANCESTOR}

The study of the process of domestication of wild animals, in particular Ovis aries, continues in our time. During the study of this issue, several species of modern wild sheep were considered as possible ancestors of the domestic sheep. According to the classification proposed by Nadler modern wild sheep are divided into 7 species, differ in morphological features, geographical distribution and diploid set of chromosomes [22]. Asian ( $O$. orientalis) and European (O. musimon) mouflon live in western Asia and Europe. On the territory of Central Asia there are two species: argali $(O$. ammon) and urial $(O$. vignei). The Ovis genus includes three more species of wild sheep, such as dall $(O$. dalli), bighorn $(O$. canadensis), snow sheep ( $O$. nivicola), which are common in the USA, Canada and Northeast Asia, respectively [13, 22].

Before the application of the cytogenetic analysis of sheep, two independent events of domestication were expected, where the ancestor of the domestic sheep is urial (O. vignei), domesticated in the Aral-Caspian basin, that further spread to the countries of the Middle East and Europe. The second lineage consisted of mouflons ( $O$. orientalis and O.musimon) that arrived in Europe after $O$. vignei and crossed with the latter. According to this hypothesis, the domestic sheep of the Middle East countries were derived from urials, and the argali (O.ammon) participated many times in the formation of Ovis aries [23].

As a result of cytogenetic studies conducted by Nadler and Woronzow, differences in chromosome sets of wild sheep were established: mouflons $(O$. orientalis and $O$. musimon $2 \mathrm{n}=54)$, urial $(O$. vignei $2 \mathrm{n}=58)$, argali $(O$. ammon $2 \mathrm{n}=56)$, dall sheep $(O$. dalli $2 \mathrm{n}=54)$ and bighorn sheep (O. canadensis $2 \mathrm{n}=54)$ [22]. The data obtained in the study of chromosome sets in the breeds of domestic sheep in Europe and Asia, indicate a complete identity of mouflon karyotype $(O$. orientalis and $O$. musimon). Consequently, the results of this study are not consistent with the hypothesis that the ancestor of the domestic sheep was urial (O. vignei). Moreover, cytogenetic analysis indicated that the ancestor of domestic sheep could be mouflons common in the southern Europe, on the islands of Corsica and Sardinia [23].

Valdez and Nadler found that the hybridization of wild species $O$. orientalis $(2 \mathrm{n}=54)$ and $O$. vignei $(2 \mathrm{n}=58)$ leads to the appearance of prolific subspecies with a diploid set of chromosomes at 54, 55, 56,57 and 58. Interestingly, the hybrid species $(2 \mathrm{n}=55)$ with $O$. ammon $(2 \mathrm{n}=56)$ produce an ovule with a set of 54 chromosomes, when prezygotic selection results in a lower number of chromosomes [24]. Consequently, having only a diploid set of chromosomes, it is impossible to determine the ancestor of Ovis aries. Additional types of analysis based on the genetics of the genus Ovis were required. An example of the hybridization of the domestic breed of sheep is the Kazakh arharomerinos breed $(n=54)$, derived by crossing $O$. ammon $(n=56)$ and merino $(n=54)$ [16].

The study of the genetics of the genus Ovis to determine the ancestor of the domestic sheep until recently relied on two main markers: mtDNA and retroviral insertions. The diversity of mtDNA haplotypes among the species made it possible to establish phylogenetic relationships at the species level. In turn, retroviral inserts have been combined into several groups, called retro-typesto find the relationship between the integration of enJSRV loci in the sheepgenome.

Results of phylogenetic analysis have shown that wild sheep O. ammon and $O$. vignei weregenetically distant from domestic sheep.Therefore as ancestor were proposed to be Asian (O. orientalis) and European mouflons $(O$. musimon) [7]. The study of aDNA in the sheep of Erlitou settlement in China (ca. 2,100-1,800 B.C.) confirmed that argali and urial are not phylogenetically associated with ancient domesticated sheep (fig. 2) [25, 26]. 


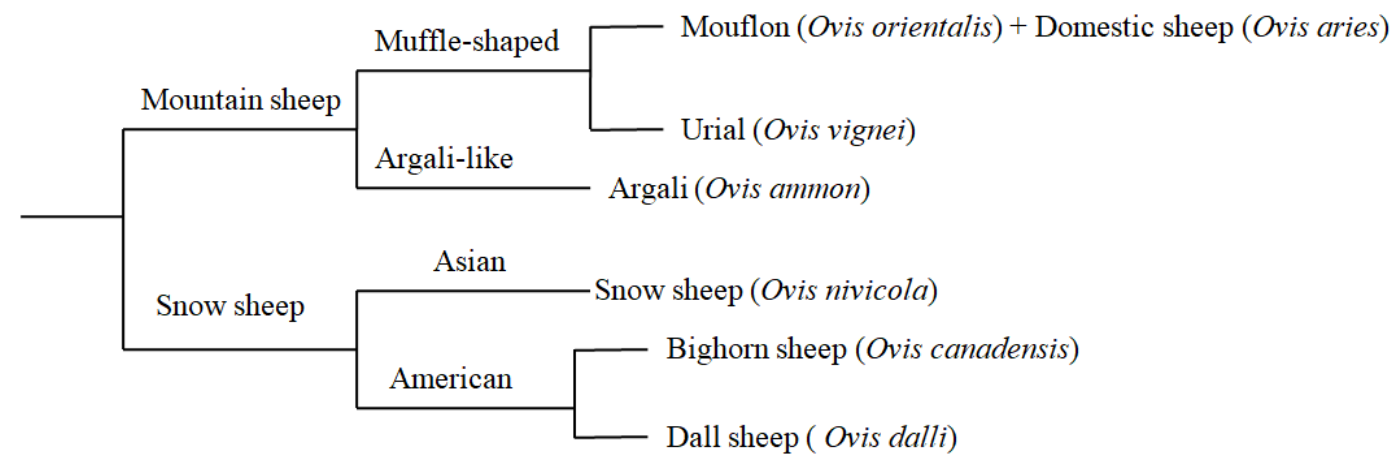

Fig. 2. Phylogenetic tree of genus Ovis

Interestingly, when comparing the mtDNA sequences of Asian and European domestic sheep breeds, the difference is $4.43 \%$. The sequence of mouflons differs from Asian breeds of domestic sheep by $4.52 \%$, and with European breeds by $1.36 \%$. These data confirmed the hypothesis that domestic sheep and mouflons originate from a common ancestor [23].

The European mouflon (O. musimon) is phylogenetically associated with haplogroup B, but Hiendleder has established that the European mouflon is a feral relative of the domesticated Asian mouflon (O. orientalis), which migrated to Europe from Asia after the Neolithic period. Consequently, modern domestic sheep originate from one or more populations of Asian mouflon (O. orientalis) [16].

The discovery of new mitochondrial haplogroups provided an opportunity to review the relationship between domestic sheep and wild species with the study of retroviral insertions. It was confirmed that the Asian mouflon $(O$. orientalis) is the ancestor of all modern sheep. It was mentioned earlier that urial, one of the closest related species of domestic sheep, whose habitat overlaps partially with the habitat of the mouflon, has different mitochondrial lineages [12]. Based on the analysis of retroviral inserts, the $O$. vignei discrepancy with domestic sheep was calculated, which amounted to be 800,000 BP. Therefore, any retrovirus locus that is present in the genome of both species will precede domestication. Separation of muflons (O. orientalis, $O$. musimon) from $O$. aries occurred much earlier, during the Middle Pleistocene $0.790 \mathrm{Ma}$, which significantly precedes the domestication event [27].

Thus, as a result of genetic studies of modern and wild sheep, it was reliably determined that the ancestor of domestic sheep is the muflon O.orientalis [7, 12].

\section{MIGRATION OF SHEEP FROM THE NEAR EAST}

The wild ancestor of the domestic sheep was an Asian mouflon (O.orientalis), which was domesticated about ca. 11,000 BPin the Fertile Crescent region to the north of the Zagros Mountains. The genetic history of the domestication of sheep has been investigated by analyzing mtDNA, and retroviral insertions in modern and ancient sheep [1]. In the study of modern sheep in the Levant countries, an increased nucleotide diversity of mtDNA sequences was observed, which confirms the existence of a geographic center of domestication in this region [12].

A large-scale study of the distribution of endogenous polymorphisms, such as retrovirus insertion sites, has identified two main migration waves for sheep: the spread of primitive sheep from the domestication center, replacing the second wave of sheep migration with improved characteristics about 5,000 BP [19].

The spread of sheep from the domestication center to Europe, Asia and Africa coincides with the introduction of the Neolithic into Mesolithic cultures [28]. According to the model of Mediterranean Neolithic expansion proposed by Ammerman and Cavalli-Sforza, the growth of the rural population slowly replaced the local huntergatherers by $1 \mathrm{~km}$ per year (fig. 3) [1]. 


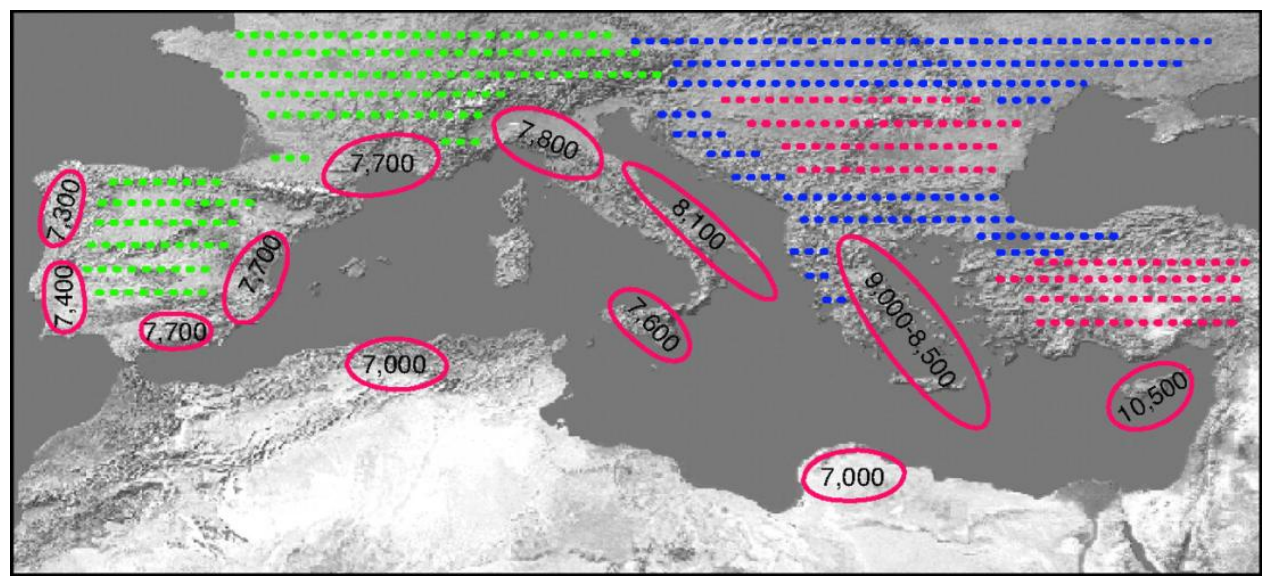

Red ellipses point to the location of farming with approximate dates of formation thousand years ago. Colored dots point to the districts, where there was planned to settle of Neolithic culture (red), was the adoption of Neolithic age (green), possible integration of farmers blue).

Fig. 3. The Neolithic distribution model in the Mediterranean Basin

Thus, from the center of domestication about 9 thousand years ago the sheep migrated to the southeast and southwest of the Fertile Crescent. Colonists transferred to Cyprus the continental fauna (10,500-9,000 BP), which is an important event in the spread of the Neolithic, since further Neolithic spreading took place in the coastal regions of Greece and the Aegean islands. In Italy, the colonists settled about 7,800 BP, in France, on the excavations (7,700-7,600 BP) of the flora and fauna of the Neolithic period, the remains of domestic sheep and wheat were found. Neolithic settlements in Spain (7,700-7,600 BP) and Portugal (7,400-7,300 BP) arose with the spread of farmers along the perimeter of the Iberian Peninsula [1]. It should be noted that Portuguese modern sheep have three lines of mitochondrial haplogroups. This genetic diversity within the breed is explained by the repeated introduction of the Ovis genus on the Iberian Peninsula from Africa and/or Europe [19].

The study of retroviral integrations of modern sheep breeds in northwestern and northern Europe showed an interesting genetic connection with the European mouflon. Among the sheep of the wool direction of productivity, there was another retroviral insert, indicating a late and second wave of sheep migration [19]. In 1991, on the border of Austria and Italy, a human mummy, widely known as the "Tyrolean man" or Ötzi, dated 5,300 BP from the Copper Age, was found. The clothing of the mummy partly consisted of sheepskin fur, a sample of the ancient sheep DNA showed a haplogroup B. Apart from the southern migration path of sheep to northern Europe, there is evidence that sheep from the Middle East came to Scandinavia through Russia [21]. Thus, the sheep have spread throughout Europe in two migration waves from the place of their domestication in the Middle East.

Migration routes of sheep in the northeast direction to Asia were laid through the Caucasus Mountains and the foothills of the Hindu Kush, Pamir in the eastern part of Central Asia. The Caucasus region is one of the earliest places of introduction of domestic sheep from the Fertile Crescent, excavations of settlements with ancient representatives of the genus Ovis date back to 8,000 BP. The second introduction of sheep into Central Asia, especially East Kazakhstan, occurred during the Bronze Age (4,500 BP) from the Middle East through the western foothills of the Pamir and the Tien-Shan [30].

Studies of sheep on the territory of Eurasia show that some species of wild sheep of southeastern Kazakhstan differ from other representatives of wild sheep of Eurasia, but domestic breeds of sheep are homogeneous with their southern relatives. It follows that the sheep of Central Asia have not migrated from the Caspian region, otherwise there would be more similarities between European and East Eurasian breeds, since both lines would contain genetic markers of wild sheep that were introduced in Europe after the initial domestication. [16]. In contrast, the breeds of European and Central Asian sheep are different, while sheep from Syria represent the closest genetically related population to domesticated Central Asian sheep [23].

The study of ancient DNA from the archaeological sites of Central Asia determined that the secondary introduction of sheep with the improvement of wool production took place in the Bronze and Iron Age [30]. Mitochondrial haplotype A prevailed in all samples, haplogroups B and C were found at each site of the collection of the remains, and D and $\mathrm{E}$ in archaeological sites in the south of Central Asia. In addition, the different frequencies of the endogenous inserts enJSRV-7 and enJSRV-18 in the samples of Bronze and Iron Age indicate the inflow of new lineages from the Middle East to Central Asia during the third millennium BP [30]. Modern breeds of sheep of Pakistan and China are homogeneous with Middle Eastern modern breeds of domestic sheep as discovered by analysis of retroviral insertions, which indicates direct migration of domestic sheep between these regions [19]. Calculations based on genogeographic analysis and the ratio of population diversity made it possible to determine that the region of the Mongolian plateau was a secondary settlement center, a "transportation hub" in the eastern part of Eurasia. Thus, it can be assumed that the sheep from the domestication center migrated through the Caucasus and 
Central Asia to the territory of China. In addition, a study of Eurasian breeds of sheep showed that migration waves occurred approximately between 6,800-4,500 BP. Specifically, for haplogroups A and B it occurred between 6,800$6,400 \mathrm{BP}$, and for haplogroup C about 4,500 BP [27].

Migration of sheep from the center of domestication coincides with the spread of the Neolithic culture from the countries of the Fertile Crescent and has three main directions, namely, Europe, Asia and Africa (fig. 4) [27]. Analysis of genetic markers supplemented archaeological knowledge on the migration history of sheep through Eurasia. Northern European breeds of sheep partly came from Russia, possibly during the second wave of domestication. The study of aDNA of sheep remains in Central Asia has revealed the time of the second wave of migration, which coincided with the Bronze Age.

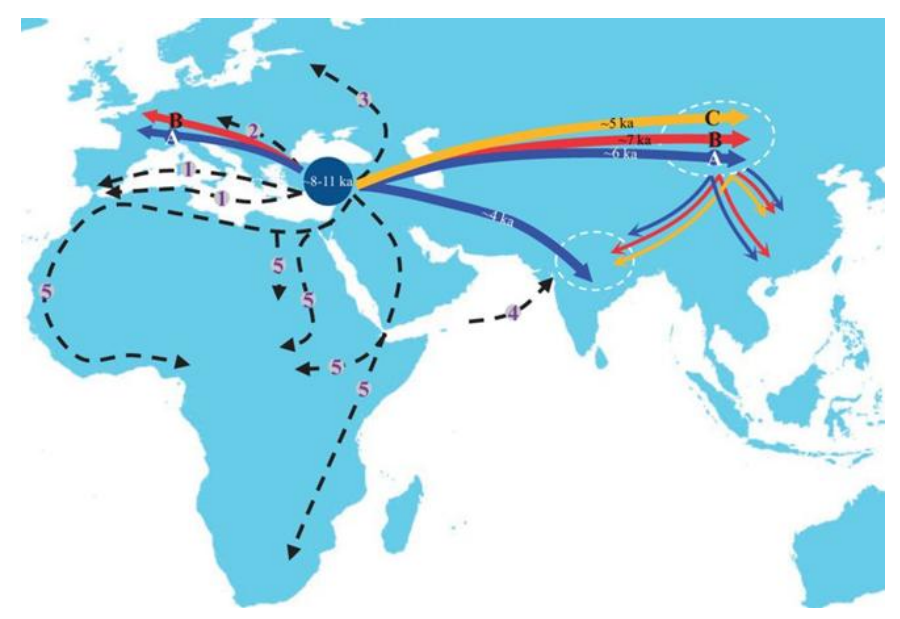

\begin{abstract}
Migration routes of gal groups are pointed with colored lines (A-blue, B- red, C-yellow). With numbers are pointed the main migration routes of sheep: Mediterranean route (1), Dunay corridor (2), Route to the north Europe (3), route to Hindustan peninsula (4), migration ways to Africa.
\end{abstract}

Fig. 4. The main migration routes for the distribution of the domestic sheep (Ovis aries)

\title{
Historical sites in Kazakhstan as evidence of sheep migration
}

The presence of Bronze and Iron Age monuments on the territory of Kazakhstan testifies to the early Neolithic cultures, in the archaeological excavations of which the remains of sheep were found. In the past and nowadays sheep farming is one of the main sources of food and wool in Central Asia.

Ancient settlements with bone remains of domesticated sheep are located in the Central and Western Kazakhstan. Archaeological monuments of Central Kazakhstan are represented by Andronovskaya (Bada burial ground, Temirkash settlement) and Begazy-Dandybaevskaya (Korzhar cemetery, Kent settlement) with cultures dating from the Bronze Age. Later in the early Iron Age Tasmolin culture was formed, represented by Karagaila monument. Botai and related Eneolithic/Early Bronze Age sites in the north-central steppe date from roughly 3500$3000 \mathrm{BC}$ and reveal faunal assemblages extremely rich in horse remains - often more than 99 per cent of all fauna [31].

Of particular interest is the location of the Toksanbay settlement (3,000-2,000 BP) on the territory of the West Kazakhstan region, since the Eastern Caspian region played a significant role in the spread of livestock in the territory of Kazakhstan, being a possible migration pathway of the first wave of domestication [32]. Toksanbai dates from the Bronze Age settlement, but the time of introduction of sheep breeding remains unknown, whether the sheep of the first wave of domestication were present, or whether they were breeds with improved characteristics of the wool $[33,34]$.

There is evidence that the ancient sheep of the southern settlements of Central Asia, such as TillaBulak $(3,900$ BP) and Kurganzhol (2,300 BP) arrived from the Middle East in the second a wave of domestication (fig. 5) [25]. 


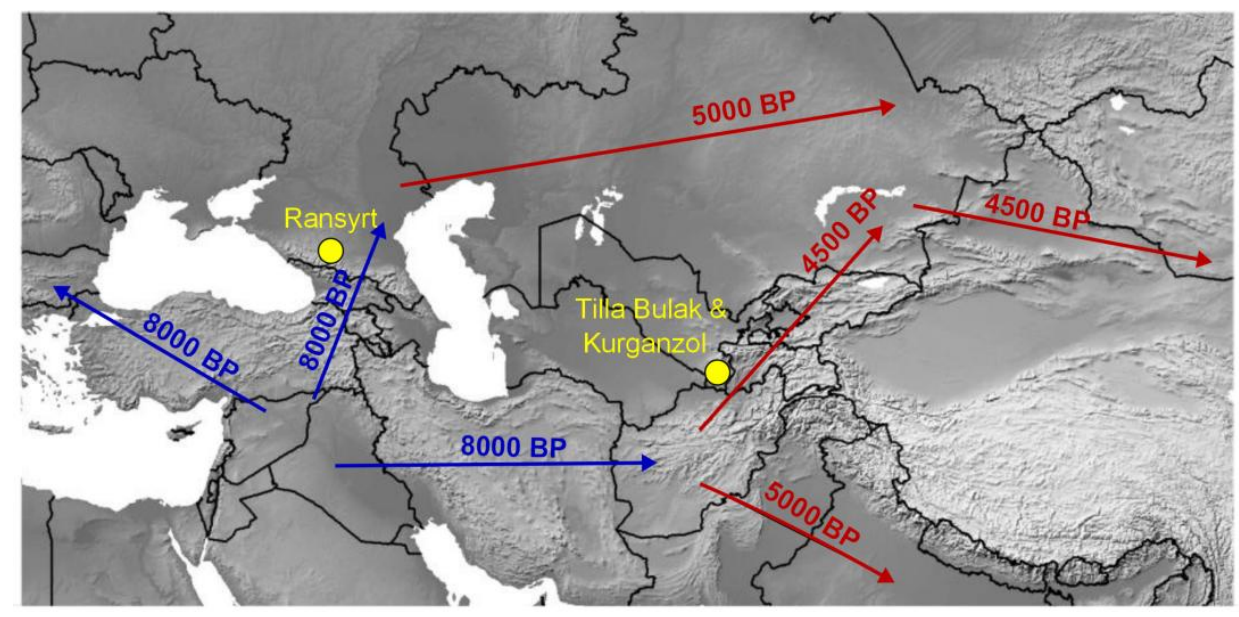

Locations of ancient settlements are pointed with yellow type. Arrows indicate the direction and time of an introduction of sheep to Central Asia (blue ones about 8000 BP, red ones about 5000-4000 BP).

Fig. 5. Migration routes of sheep to Central Asia

The high incidence of haplogroup B in modern breeds of Central Asian sheep, particularly Kazakhstan, may be the result of the secondary introduction of domestication. On the other hand, a study of the sheep of an ancient settlement in the North Caucasus, dating back to 3,600 BP, showed that when comparing the ancient genomes of sheep with modern breeds in this area, the latter have less genetic diversity [30]. Consequently, the ancient sheep may have been similar to the primitive North European breeds, which are distinguished by coarse wool, which could have been introduced with the first wave of domestication [35].

Perhaps the first wave of domestication came to the territory of Kazakhstan with the Neolithic culture through the Caucasus, from there across the top from the Caspian Sea to the east. In this case, the migration path of the second domestication wave most likely began from the Middle East through the south of Central Asia and further spread to the territory of Kazakhstan. This hypothesis is confirmed by the uniform distribution of haplogroups A and B in the territory of Central Asia [17].

\section{CONCLUSION}

To date, archaeological evidences indicate that modern sheep breeds were domesticated 11,000 BP in the Fertile Crescent. The ancestor of the domestic sheep is Asian mouflon (Ovis orientalis).Domestication occurred from a mixed population of wild sheep, as evidenced by the diversity of SNPs in modern breeds of sheep around the world. Five different mtDNA haplogroups testify to multiple events of domestication and subsequent introgression between domestic sheep and their wild species.Migration of sheep from the center of domestication coincides with the spread of the Neolithic culture from the countries of the Fertile Crescent and has three main directions, namely, Europe, Asia and Africa. Sheep migrated toCentral Asia in two stages with a time lapse of several millennia. Despite extensive studies in the study of the history of domestication of Ovis aries, the questions of the phenotype of ancient sheep remain open, it is not clear whether the selection was carried out according to certain criteria, what was the sheep population of the second domestication wave, whether it was domesticated species, or wild species of sheep that was selected. Further genetic studies of modern and ancient samples of sheep are needed to expand the understanding of the domestication events, migration processes and the formation of basic breeds of domestic sheep.

\section{Funding}

This study was supported by Ministry of Education and Science of the Republic of Kazakhstan (grant no. $0389 / \mathrm{GF} 4)$.

\section{REFERENCES}

1. Zeder M.A. Domestication and early agriculture in the Mediterranean Basin: Origins, diffusion, and impact. Proc. Natl. Acad. Sci., 2008, vol. 105, no. 33, pp. 11597-11604. doi: 1073/pnas.0801317105.

2. Hiendleder S., Hecht W., Dzapo V., Wassmuth R. Ovine mitochondrial DNA: Restriction enzyme analysis, mapping and sequencing data. Anim. Genet., 1991, vol. 23, pp. 151-160. https://doi.org/10.1111/j.13652052.1992.tb00034.x.

3. Kijas J.W., Lenstra J.A., Hayes B., et al. Genome-wide analysis of the world's sheep breeds reveals high levels of historic mixture and strong recent selection. PLoS Biol., 2012, vol. 10, no. 2, pp. e1001258. doi: 
10.1371/journal.pbio.1001258.

4. Larson G., Fuller D.Q. The Evolution of Animal Domestication. Annu. Rev. Ecol. Evol. Syst, 2014, vol. 45, no. 1, pp. 115-136. doi: 10.1146/annurev-ecolsys-110512-135813.

5. Gepts P., Famula T.R., Bettinger R.L., et al. Biodiversity in Agriculture: Domestication, Evolution, and Sustainability. Cambridge, Cambridge University Press, 2012, 606 p. doi: 10.1017/CBO9781139019514.

6. Scheu A. Neolithic animal domestication as seen from ancient DNA. Quat. Int., 2016, pp. 1-6. doi: 10.1016/j.quaint.2017.02.009.

7. Hiendleder S., Lewalski H., Wassmuth R. The complete mitochondrial DNA sequence of the domestic sheep (Ovis aries) and comparison with the other major ovine haplotype. J. Mol. Evol., 1998, vol. 47, pp. 441-448. doi: 10.1007/PL00006401.

8. Wood N.J., Phua S.H. Variation in the control region sequence of the sheep mitochondrial genome. Anim. Genet., 1996, vol. 27, no. 1, pp. 25-33. doi: 10.1111/j.1365-2052.1996.tb01173.x.

9. Guo J., Du L.X., Ma Y.H., et al. A novel maternal lineage revealed in sheep (Ovis aries). Anim. Genet., 2005, vol. 36, no. 4, pp. 331-336. doi: 10.1111/j.1365-2052.2005.01310.x.

10. Pedrosa S., Uzun M., Arranz J-J., Gutierrez-Gil B., San Primitivo F., Bayon Y. Evidence of three maternal lineages in near eastern sheep supporting multiple domestication events. Proceedings of the Royal Society B. Biol. Sci., 2005, vol. 272, pp. 2211-2217. doi: 10.1098/rspb.2005.3204.

11. Pereira F., Davis J. M., Pereira L., McEvoy B., Bradley D.G. Genetic Signatures of a Mediterranean Influence in Iberian Peninsula Sheep Husbandry. Molecular Biology and Evolution, 2006, vol. 23, no. 7, pp. 14201426. https://doi.org/10.1093/molbev/ms1007.

12. Meadows J.R.S., Cemal I., Karaca O., Gootwine E., Kijas J.W. Five ovine mitochondrial lineages identified from sheep breeds of the near east. Genetics, 2007, vol. 175, no. 3, pp. 1371-1379. doi: 10.1534/genetics.106.068353.

13. Demirci S., Koban Baştanlar E., Dağtaş N.D., et al. Mitochondrial DNA diversity of modern, ancient and wild sheep (Ovis gmelinii anatolica) from Turkey: new insights on the evolutionary history of sheep. PLoS One, 2013, vol. 8, no. 12, pp. e81952. doi: 10.1371/journal.pone.0081952.

14 Tapio M., Marzanov N., Ozerov M., et al. Sheep mitochondrial DNA variation in European, Caucasian, and Central Asian areas. Mol. Biol. Evol., 2006, vol. 23, no. 9, pp. 1776-1783. doi: 10.1093/molbev/ms1043.

15. Meadows J.R.S., Hiendleder S., Kijas J.W. Haplogroup relationships between domestic and wild sheep resolved using a mitogenome panel. Heredity (Edinb), 2011, vol. 106, no. 4, pp. 700-706. doi: 10.1038/hdy.2010.122.

16. Hiendleder S., Kaupe B., Wassmuth R., Janke A. Molecular analysis of wild and domestic sheep questions current nomenclature and provides evidence for domestication from two different subspecies. Proc. R. Soc. Lond., 2002, vol. 269, pp. 893-904. doi: 10.1098/rspb.2002.1975.

17. Meadows J.R.S., Li K., Kantanen J., et al. Mitochondrial Sequence Reveals High Levels of Gene Flow Between Breeds of Domestic Sheep from Asia and Europe. J. Hered., 2005, vol. 96, no. 5, pp. 494-501. doi: 10.1093/jhered/esi100.

18. Armezzani A., Varela M., Spencer T., Palmarini M., Arnaud F. "Ménage à Trois" The Evolutionary Interplay between JSRV, enJSRVs and Domestic Sheep. Viruses, 2014, vol. 6, no. 12, pp. 4926-4945. https://doi.org/10.3390/v6124926.

19. Chessa B., Pereira F., Arnaud F., et al. Revealing the history of sheep domestication using retrovirus integrations. Science, 2009, vol. 324, pp. 532-536. doi: 10.1126/science.1170587.

20. Meadows J.R.S., Hanotte O., Drögemüller C. et al. Globally dispersed Y chromosomal haplotypes in wild and domestic sheep. Anim. Genet., 2006, vol. 37, no. 5, pp. 444-453. doi: 10.1111/j.1365-2052.2006.01496.x.

21. Niemi M., Bläuer A., Iso-Touru T., et al. Mitochondrial DNA and Y-chromosomal diversity in ancient populations of domestic sheep (Ovis aries) in Finland: comparison with contemporary sheep breeds. Genet. Sel. Evol., 2013, vol. 45, pp. 1-14. doi: 10.1186/1297-9686-45-2.

22. Rezaei H.R., Naderi S., Chintauan-Marquier I.C., et al. Evolution and taxonomy of the wild species of the genus Ovis (Mammalia, Artiodactyla, Bovidae). Mol. Phylogene.t Evol., 2010, vol. 54, no. 2, pp. 315-326. doi: 10.1016/j.ympev.2009.10.037.

23. Hiendleder S., Mainz K., Plante Y., Lewalski H. Analysis of mitochondrial DNA indicates that domestic sheep are derived from two different ancestral maternal sources: No evidence for contributions from urial and argali sheep. J. Hered., 1998, vol. 89, no. 2, pp. 113-120. doi: 10.1093/jhered/89.2.113.

24. Mason I.L. Evolution of Domesticated Animals. Longman, New York, 1984, 452 p.

25. Cai D.W., Han L., Zhang X.L., Zhou H., Zhu H. DNA analysis of archaeological sheep remains from China. J. Archaeol. Sci., 2007, vol. 34, no. 9, pp. 1347-1355. doi: 10.1016/j.jas.2006.10.020.

26. Genus Ovis. Available https://ru.wikipedia.org/wiki/\%D0\%91\%D0\%B0\%D1\%80\%D0\%B0\%D0\%BD\%D1\%8B (accessed at 14 March 2018).

27. Lv F.H., Peng W.F., Yang J., et al. Mitogenomic meta-analysis identifies two phases of migration in the history of Eastern Eurasian sheep. Mol. Biol. Evol., 2015, vol. 32, no. 10, pp. 2515-2533. doi: 10.1093/molbev/msv139. 
28. Olivieri C., Ermini L., Rizzi E., et al. Phylogenetic position of a copper age sheep (Ovis aries) mitochondrial DNA. PLoS One, 2012, vol. 7, no. 3, pp. e33792. doi: 10.1371/journal.pone.0033792.

29. Niemi M., Bläuer A., Iso-Touru T., et al. Mitochondrial DNA and Y-chromosomal diversity in ancient populations of domestic sheep (Ovis aries) in Finland: comparison with contemporary sheep breeds. Genet. Sel. Evol., 2013, vol. 45, pp. 1-14. doi: 10.1186/1297-9686-45-2.

30. Schroeder O., Benecke N., Frölich K., et al. Endogenous retroviral insertions indicate a secondary introduction of domestic sheep lineages to the caucasus and Central Asia between the Bronze and Iron Age. Genes (Basel), 2017, vol. 8, no. 6, pp. 1-7. doi: 10.3390/genes8060165.

31. Frachetti M., Benecke N.. From sheep to (some) horses: 4500 years of herd structure at the pastoralist settlement of Begash (south-eastern Kazakhstan). Antiquity, 2009, vol. 83, no. 322, pp. 1023-1037. doi: 10.1017/S0003598X00099324.

32. Mochalov O. D. K voprosu o kulturnyh komponentah v keramike jepohi srednej bronzy stepnogo Priuralja [On the issue of cultural components in ceramics of the Middle Bronze Age of the steppe Priuralye]. Izvestija Samarskogo nauchnogo centra Rossijskoj akademii nauk [News of the Samara Scientific Center of the Russian Academy of Sciences], 2010, vol. 12, no. 6, p. 6.

33. Loshakova T.N., Gavrilov D.A. Mikrobiomorfnye issledovanija kul'turnogo sloja poselenija Ajtman (plato Ustjurt) [Microbiomorphic studies of the cultural layer of the Aitman settlement (Ustyurt plateau)]. Vestnik arheologii, antropologii i jetnografii [Herald of Archeology, Anthropology and Ethnography], 2015, vol. 2, no. 29, p. 9.

34. Nekrasov A.E., Kosintsev P.A., Samashev Z. et al. New data on avifauna of the Ustyurt plateau in the Holocene. Dokl. Biol. Sci., 2016, vol. 469, no. 1, pp. 170-172.

35. Frachetti M.D. Multiregional Emergence of Mobile Pastoralism and Nonuniform Institutional Complexity across Eurasia. Curr. Anthropol., 2012, vol. 53, no. 1, pp. 2-38. doi: 10.1086/663692. 